\title{
Evaluation of Mechanical Properties of Ti/Al/Zr-N and Zr/Al/Ti-N Thin Films
}

\author{
CD Gómez-Esparza ${ }^{1}$, RP Talamantes-Soto ${ }^{1}$ and A Duarte-Moller ${ }^{1,2^{*}}$
}

1. Centro de Investigación en Materiales Avanzados (CIMAV), Miguel de Cervantes No. 120, Chihuahua, Chih., México.

2. Escuela de Ingeniería Civil, Industrial y Mecánica, Universidad De La Salle Bajío, Av. Universidad 602, León, Gto., Mexico.

* Corresponding author: jduarte@delasalle.edu.mx

Hard coatings in the form of a thin film have been very useful in improving the wear resistance of the materials in service. Ternary nitride coatings have been presented as a solution to this problem. Two multi-layer thin films, Ti/Al/Zr-N and $\mathrm{Zr} / \mathrm{Al} / \mathrm{Ti}-\mathrm{N}$ were deposited on silicon substrate by using the INTERCOVAMEX-V3 DC sputtering system [1, 2]. Substrate temperature was of $300{ }^{\circ} \mathrm{C}$ and $200 \mathrm{~W}$ in the pulsed DC. The multilayer was obtained by growing $\mathrm{ZrN}$ on $\mathrm{Si}$ at a nitrogen flow of $4 \mathrm{~cm}^{3} / \mathrm{min}$ during 15 minutes following of growing Ti and $\mathrm{Al}$ with $6 \mathrm{~cm} 3 / \mathrm{min}$ for 15 minutes and finally $\mathrm{ZrN}$ at 6 $\mathrm{cm}_{3} /$ min during 15 minutes.

Nanoindentation tests were performed in order to understand the mechanical properties of the coatings. Mechanical properties were obtained using an Agilent Nano Indenter G200 equipped with a Dynamic Contact Module (DCM) indentation head, and a Berkovich diamond indenter tip. The calibration procedure was performed using a standard specimen of fused silica. Focused ion beam (FIB) method was used for the cross section specimen preparation for TEM observations. The thickness of each layer of coatings was measured from cross-sectional TEM micrographs and the values for both coatings are summarized in Table 1. The nanoindentation tests were performed to control the depth of indentation and avoid the effects from the material beneath it. The results of hardness $(\mathrm{H})$ and Young's modulus (E) are also tabulated in Table 1.

The depth-sensing nanoindentation testing reveled that hardness increases as a function of displacement for the $\mathrm{Ti} / \mathrm{Al} / \mathrm{Zr}$ array, while the increase of modulus with respect to the displacement is not significant. On the other hand, the mechanical properties of the $\mathrm{Zr} / \mathrm{Al} / \mathrm{Ti}$ coating decrease significantly with the displacement. This suggests that individual contribution of each layer in the $\mathrm{Zr} / \mathrm{Al} / \mathrm{Ti}$ array generates a profile of mechanical properties that vary considerably with the displacement. Moreover, the Ti/Al/Zr array induces an improvement of mechanical properties of the composite coating in comparison with the contribution of first layer. TEM micrographs of the multi-layer Ti/Al/Zr-N thin film are shown in Fig. 1.

Hard coatings are mainly intended to increase the service life of functional parts by providing a surface with enhanced wear resistance. Nanoscratch testing was performed in the Ti/Al/Zr thin film to detect surface damage. The total scratch length was $10 \mu \mathrm{m}$, using a load of $2.5 \mathrm{mN}$ and a wear velocity of 10 $\mu \mathrm{m} / \mathrm{s}$. Scratches were observed by scanning electron microscopy to determine if spallation of the coating around the scratch had occurred. The Fig. 2 shows the scratch pattern obtained, initially plastic deformation is observed, later the coating is partially separated, presenting a cohesive failure. However, a chipping phenomenon or cracks at the side of the scratch was not observed. 
References:

[1] VG Zavodinsky and YG Kabaldin, The Jour. Of Adhesion. 26 (2) (2019).

[2] S Chinsakolthanakorn et al., Mat. Sci. and Appl. 4 (2013).

\begin{tabular}{lrcccc}
\hline Thin Film & Layer & Thickness & Displacement $(\mathrm{nm})$ & $\mathrm{H}(\mathrm{GPa})$ & $\mathrm{E}(\mathrm{GPa})$ \\
\hline Ti/Al/Zr-N & $\mathrm{Ti}$ & 60 & 60 & 4.8 & 133 \\
& $\mathrm{Al}$ & 100 & 130 & 8.0 & 156 \\
& $\mathrm{Zr}$ & 30 & 170 & 9.4 & 170 \\
\hline $\mathrm{Zr} / \mathrm{Al} / \mathrm{Ti}-\mathrm{N}$ & $\mathrm{Zr}$ & 40 & 25 & 30.0 & 327 \\
& $\mathrm{Al}$ & 80 & 60 & 20.0 & 252 \\
& $\mathrm{Ti}$ & 35 & 140 & 16.0 & 198 \\
\hline
\end{tabular}

Table 1. Mechanical properties of thin films.
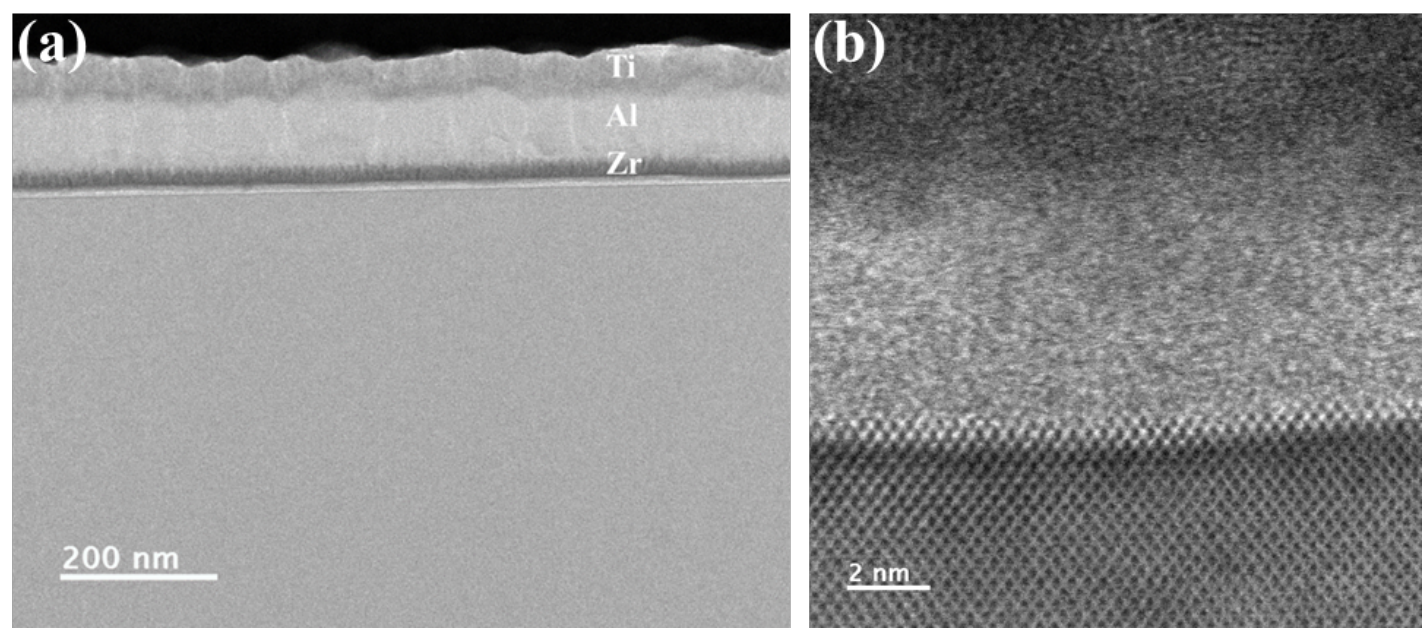

Figure 1. Cross-sectional TEM micrographs of Ti/Al/Zr thin film.
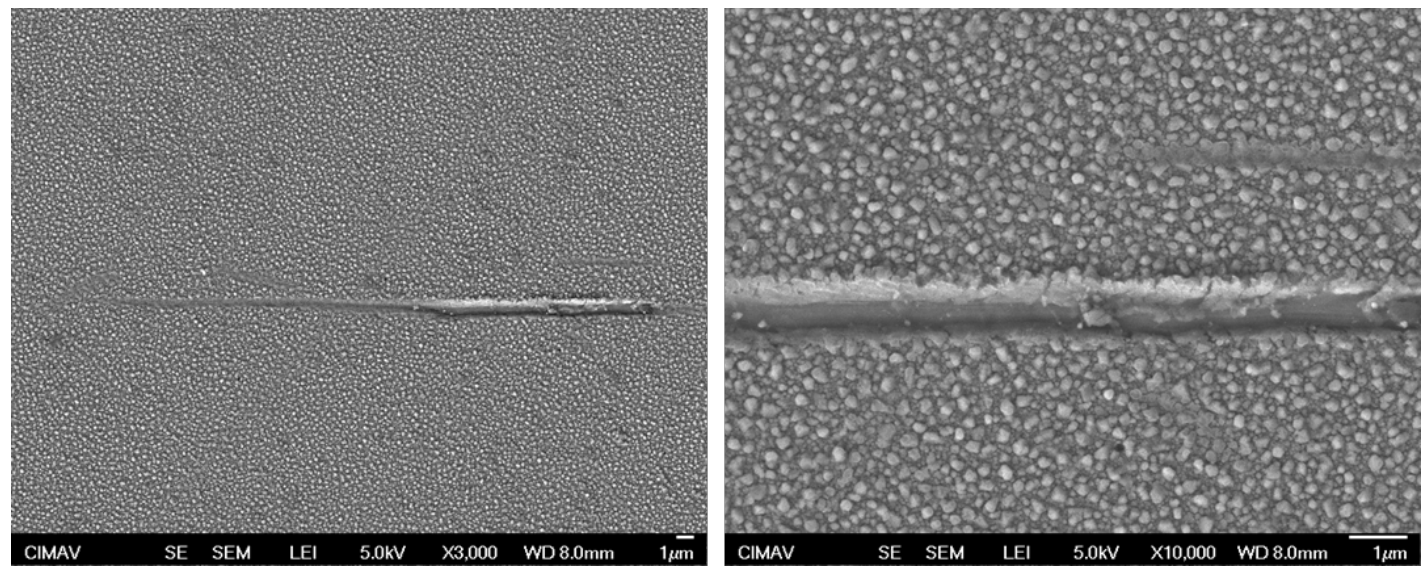

Figure 2. SEM micrographs of a scratched $\mathrm{Ti} / \mathrm{Al} / \mathrm{Zr}$ thin film. 